\title{
Sensitivity Evaluation of the Daily Thermal Predictions of the AGR-1 Experiment in the Advanced Test Reactor
}

ICAPP 2011

Grant Hawkes

James Sterbentz

John Maki

U.S. Department of Energy

National Laboratory

operated by

Battelle Energy Alliance

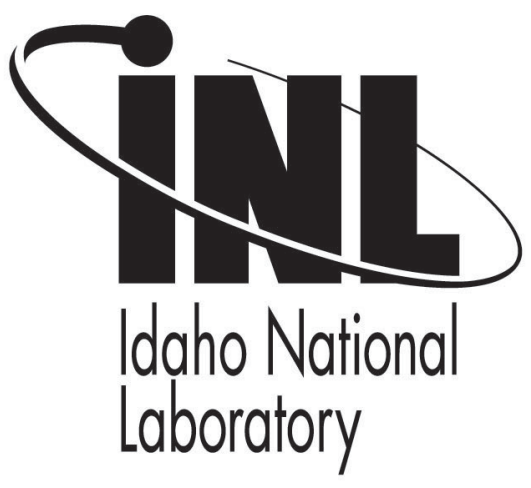

This is a preprint of a paper intended for publication in a journal or proceedings. Since changes may be made before publication, this preprint should not be cited or reproduced without permission of the author. This document was prepared as an account of work sponsored by an agency of the United States Government. Neither the United States Government nor any agency thereof, or any of their employees, makes any warranty, expressed or implied, or assumes any legal liability or responsibility for any third party's use, or the results of such use, of any information, apparatus, product or process disclosed in this report, or represents that its use by such third party would not infringe privately owned rights. The views expressed in this paper are not necessarily those of the United States Government or the sponsoring agency. 


\title{
Sensitivity Evaluation of the Daily Thermal Predictions of the AGR-1 Experiment in the Advanced Test Reactor
}

\author{
Grant Hawkes, James Sterbentz, John Maki \\ Idaho National Laboratory \\ 2525 Fremont, MS 3870 \\ +1(208) 526-8767 Grant.Hawkes@inl.gov
}

\begin{abstract}
A temperature sensitivity evaluation has been performed for the AGR-1 fuel experiment on an individual capsule. A series of cases were compared to a base case by varying different input parameters into the ABAQUS finite element thermal model. These input parameters were varied by $\pm 10 \%$ to show the temperature sensitivity to each parameter. The most sensitive parameters are the outer control gap distance, heat rate in the fuel compacts, and neon gas fraction. Thermal conductivity of the compacts and graphite holder were in the middle of the list for sensitivity. The smallest effects were for the emissivities of the stainless steel, graphite, and thru tubes. Sensitivity calculations were also performed varying with fluence. These calculations showed a general temperature rise with an increase in fluence. This is a result of the thermal conductivity of the fuel compacts and graphite holder decreasing with fluence.
\end{abstract}

\section{INTRODUCTION}

A sensitivity evaluation has been performed for the daily thermal analyses performed on the advanced gascooled reactor (AGR) experiment (AGR-1) in the Advanced Test Reactor (ATR). Six capsules were analyzed for each day of the experiment as discussed in Ref [1]. This paper discusses the sensitivity to various input parameters for one capsule (Capsule 4) at one point in time during the irradiation. Thirty different runs were performed for this sensitivity analysis.

Several fuel and material irradiation experiments, which support the development of the Next Generation Nuclear Plant (NGNP), are planned for the Advanced Gas Reactor Fuel Development and Qualification Program. The goals of these experiments are to: provide irradiation performance data to support fuel process development, qualify fuel for normal operating conditions, support development and validation of fuel performance and fission product transport models and codes, and provide irradiated fuel and materials for post-irradiation examination and safety testing. AGR-1 was the first in this series of planned experiments to test tri-isotropic (TRISO)coated, low-enriched uranium oxycarbide fuel. The AGR-1 experiment was intended to serve as a shakedown test of the multiple capsule test train designs to be used in subsequent irradiations and to test early variants of the fuel produced under this program.

The AGR-1 experiment is comprised of six individual capsules, approximately $0.034925 \mathrm{~m}$ diameter by $0.1524 \mathrm{~m}$ long, stacked on top of each other to form the test train. Each capsule contains 12 fueled compacts that are approximately $0.0127 \mathrm{~m}$ diameter by $0.0254 \mathrm{~m}$ long. The compacts are composed of fuel particles bound together by a carbon matrix. Each compact contains approximately 4,150 fissile particles ( $35 \mathrm{vol} \%$ particle packing fraction). Each capsule is supplied with a flowing helium/neon gas mixture to control the test temperature and sweep any fission gases that are released to the fission product monitoring system. Temperature control is accomplished by adjusting the gas mixture ratio of the two gases (helium and neon) with differing thermal conductivities.

A control gas gap designed to be $0.000279 \mathrm{~m}$ was implemented in the model. A nominal ATR east lobe source power of $22.47 \mathrm{MW}$ was used to normalize the power amplitude in the thermal analysis. The finite element stress and heat transfer code ABAQUS in Ref [2] was used to perform the thermal analysis.

The AGR-1 experiment was placed in the B-10 position in the ATR core as shown in Fig 1. Each capsule contains a graphite holder with three equally spaced fuel compact holder openings as shown in Fig 2. Each holder opening accommodates four axially stacked fuel compacts. Thus, each capsule has three stacks by four fuel compacts per stack for a total of 12 fuel compacts per capsule, with the entire AGR 1 experiment capsule assembly having six capsules by 12 fuel compacts per capsule for a total of 72 fuel compacts.

Fig 3 shows the axial arrangement for Stack-1. The ABAQUS model has a direct volume-for-volume correlation with the physics model discussed in Reference [3] for the heating of the compacts (each compact is evenly axially divided into two equal parts). An axial cut of a typical capsule is shown in Figure 4. 


\section{MODEL DESCRIPTION}

Figures 5 through 9 are used in the description of the model. The finite element mesh is discussed first, followed by a description of the material properties, and ending with the volumetric heat rates imposed on the model

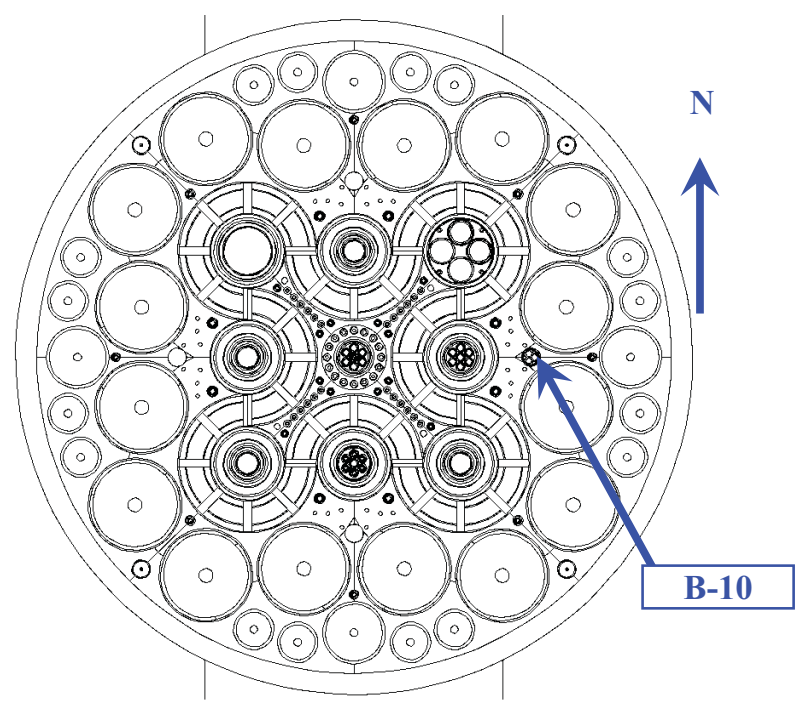

Fig 1. Cross section view of the ATR core, B-10 irradiation test position.

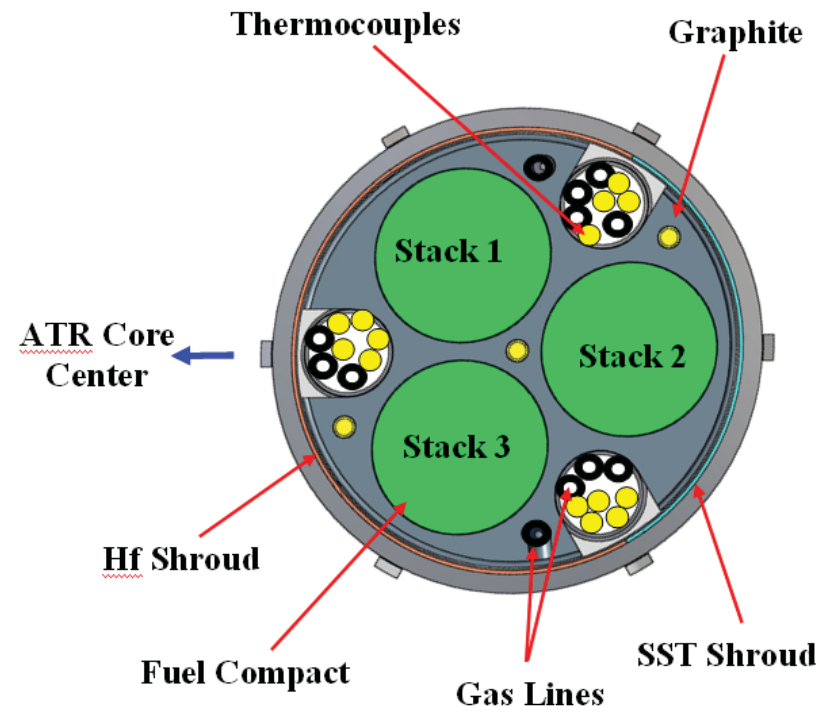

Fig 2. Schematic of cross section of an AGR-1 capsule.

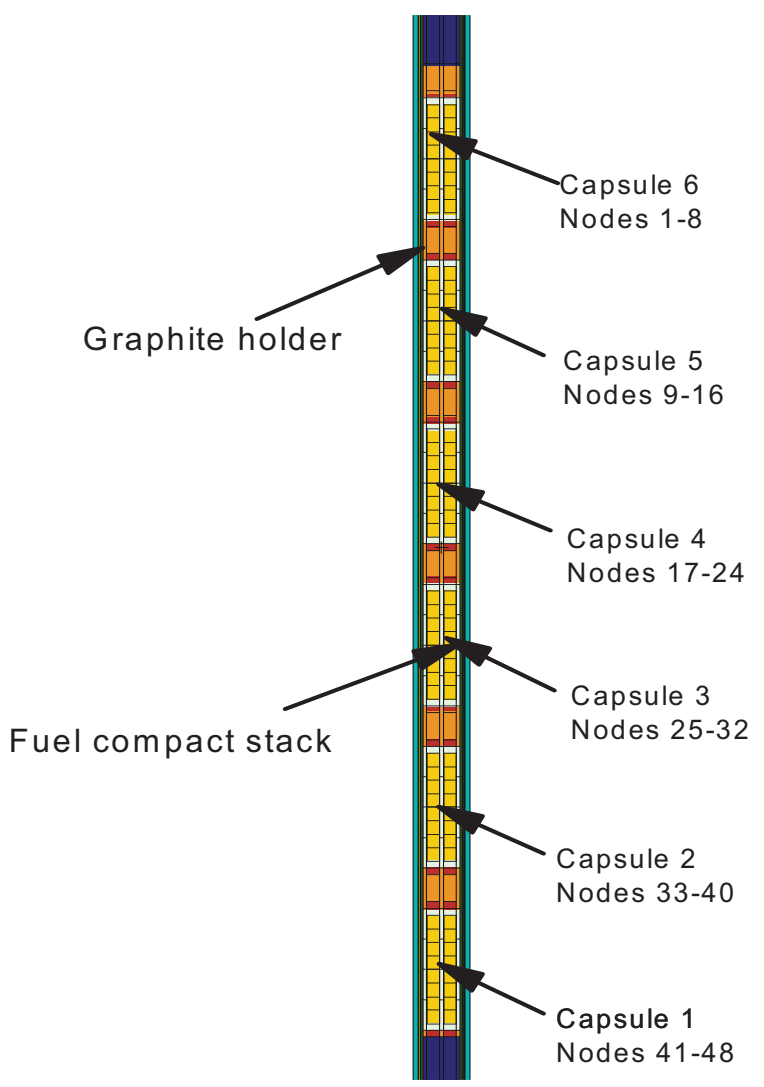

Fig 3. Axial cross-section view of the six capsules in an AGR-1 experiment capsule assembly.

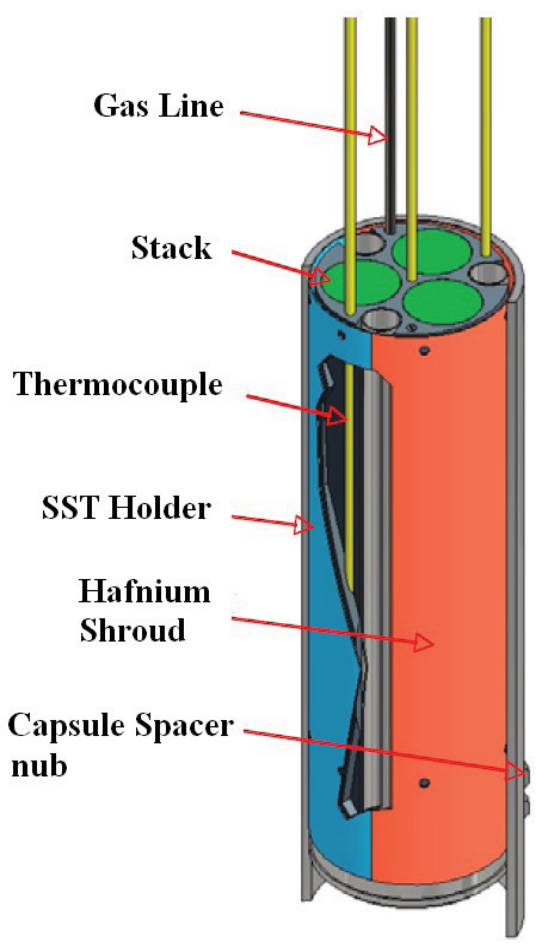

Fig 4. Three-dimensional cutaway rendering of single AGR-1 capsule. 


\section{II.A. Finite Element Mesh}

Fig 5 shows the finite element mesh with a cutaway view of the entire model. Approximately 350,000 eightnoded hexahedral brick elements were entirely used in all the models. A set of conduction-convection elements was used to model the flow of the water. All other elements were modeled solely for diffusion heat transfer.

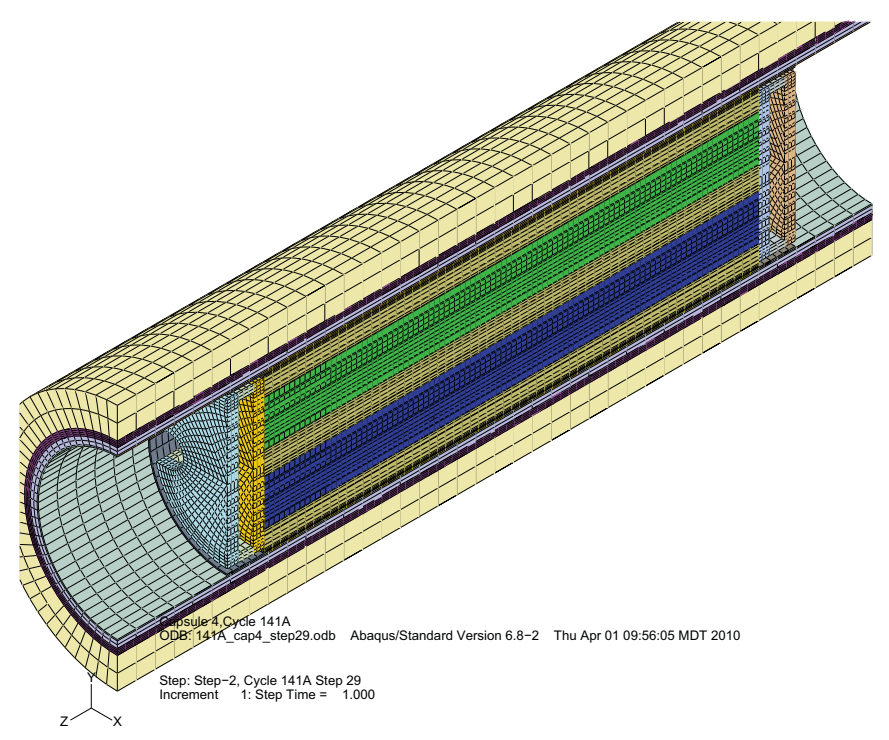

Fig 5. Sideways cutaway view of mesh with colored
entities.

The graphite holder and fuel compacts were modeled as $0.1016 \mathrm{~m}$ lengths, but most of the heat comes from the fuel compacts and not from the outer components. The water is the ultimate heat sink for each capsule. The graphite holder with its two end-cap spacers and ring were modeled for the inner part of the model. A radiation boundary sink temperature of $\left(204.4^{\circ} \mathrm{C}\right)$ is placed on the top and bottom of each graphite end cap. This value came from previous models discussed in Reference [1] for typical operating conditions.

\section{II.B. Compact Thermal Conductivity}

The fuel compact thermal conductivity was taken from correlations presented from Gontard in Reference [3] which gives correlations for conductivity, taking into account temperature, temperature of heat treatment, neutron fluence, and TRISO-coated particle packing fraction. In this work, the convention used to quantify neutron damage to a material is fast fluence $\mathrm{E}>0.18 \mathrm{MeV}$, yet in the work by Gontard [4], the unit used was the dido nickel equivalent (DNE). In order to convert from the DNE convention to the fast fluence $>0.18 \mathrm{MeV}$, the following conversion was used:

$$
\Gamma_{>0.18 \mathrm{MeV}}=1.52 \Gamma_{\mathrm{DNE}}
$$

where $\Gamma$ is neutron fluence in either the $>0.18 \mathrm{MeV}$ unit or DNE. The correlations in the report by Gontard [4] were further adjusted to account for differences in fuel compact density. The correlations were developed for a fuel compact matrix density of $1.75 \mathrm{~g} / \mathrm{cm}^{3}$, whereas the compact matrix used in AGR-1 had a density of approximately $1.3 \mathrm{~g} / \mathrm{cm}^{3}$. The thermal conductivities were scaled according to the ratio of densities $(0.74)$ in order to correct for this difference.

Fig 6 shows a three-dimensional plot of the fuel compact thermal conductivity varying with fluence and temperature. For fluences greater than $1.0 \mathrm{x} 10^{25}$ neutrons $/ \mathrm{m}^{2}(\mathrm{E}>0.18 \mathrm{MeV})$, the conductivity increases as fluence increases for higher temperatures, while the opposite occurs at lower temperatures because of the annealing of radiation-induced defects in the material with high temperatures.

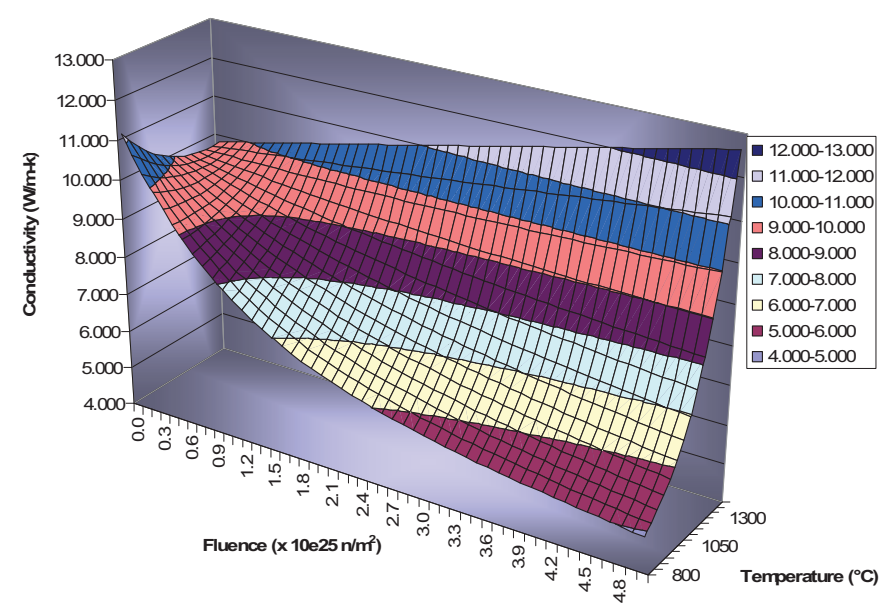

Fig 6. Three-dimensional plot of fuel compact thermal conductivity (W/m-K) varying with fluence and temperature.

\section{II.C. Graphite Thermal Conductivity}

Unirradiated graphite thermal conductivity data for the holders were provided by GrafTech [5]. Fig 7 shows unirradiated thermal conductivity of four different types of boronated graphite. The percentages indicate the weight percent $(\mathrm{wt} \%)$ boron present in the material. The 5.5\% against grain (was used in the holders for Capsules 1 and 6, while the 7\% against grain was used in Capsules 2-5. The higher boron content was placed in the interior capsules (2-5) as these locations experience a greater thermal neutron flux than the two outer capsules (1 and 6) and the higher boron content provided a flatter compact heating profile through the irradiation. The types of graphite used are indicated with arrows in the legend of Fig 7. 


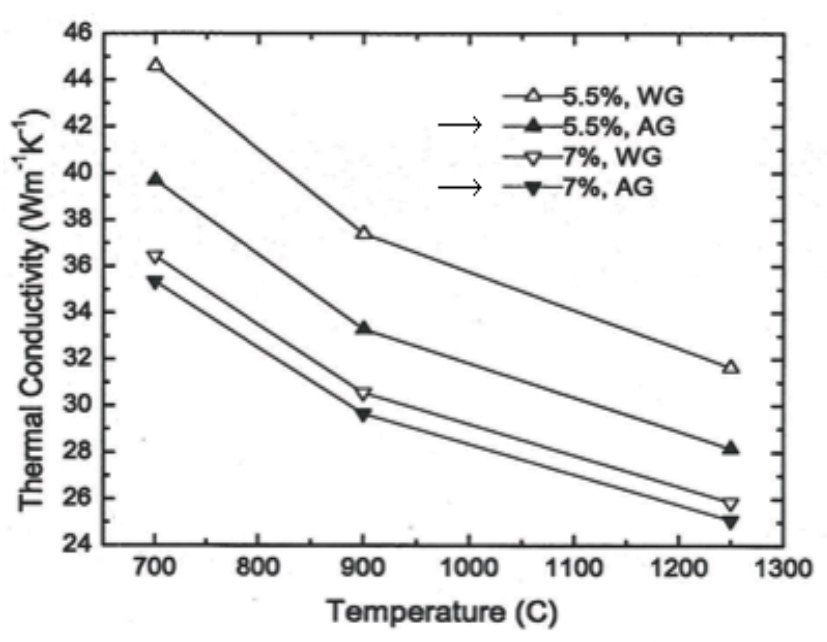

Fig 7. Thermal conductivity (W/m-K) of unirradiated, boronated graphite holders [5].

The effect of irradiation on the thermal conductivity of the graphite was accounted for in this analysis using the following correlation by Snead [6]:

$$
\begin{gathered}
\frac{k_{\text {irr }}}{k_{0}}=\left(0.25-0.00017 * T_{\text {irr }}\right) *-1.0 * \log (d p a) \\
+0.00683 * T_{\text {irr }}
\end{gathered}
$$

where $k_{\text {irr }}$ and $k_{0}$ are thermal conductivity of unirradiated and irradiated graphite, respectively, $T_{i r r}$ is the irradiation temperature $\left({ }^{\circ} \mathrm{C}\right)$, and $d p a$ is displacements per atom. The multiplier used to convert fast fluence $(>0.18 \mathrm{MeV})$ to dpa is $8.23 \times 10^{-26} \mathrm{dpa} /\left(\mathrm{n} / \mathrm{m}^{2}\right)$ and comes from Sterbentz [7]. Fig 8 shows a three-dimensional plot of this ratio $\left(k_{i r r} / k_{o}\right)$ varying with dpa and temperature. The ratio of unirradiated to irradiated thermal conductivity increases for higher temperatures and decreases for higher dpa.

\section{II.D. Gas Mixture Thermal Conductivity}

Heat produced in the fuel compacts is transferred through the gas gaps surrounding the compacts into the graphite holder via a gap conductance model using the gap width and the conductivity of the sweep gas as discussed below. Since the temperature difference between the compacts and the holder is so small, no radiative heat transfer was considered across this gap. Heat is transferred across the outer sweep gas flow region between the outside of the graphite holder and the inside of the stainless-steel liner via radiation between the two surfaces and conduction through the helium/neon sweep gas. Because the thermal capacitance of the sweep gas is very low $(30 \mathrm{cc} / \mathrm{min})$, advection is not considered in the sweep gas, and it is modeled as stationary.

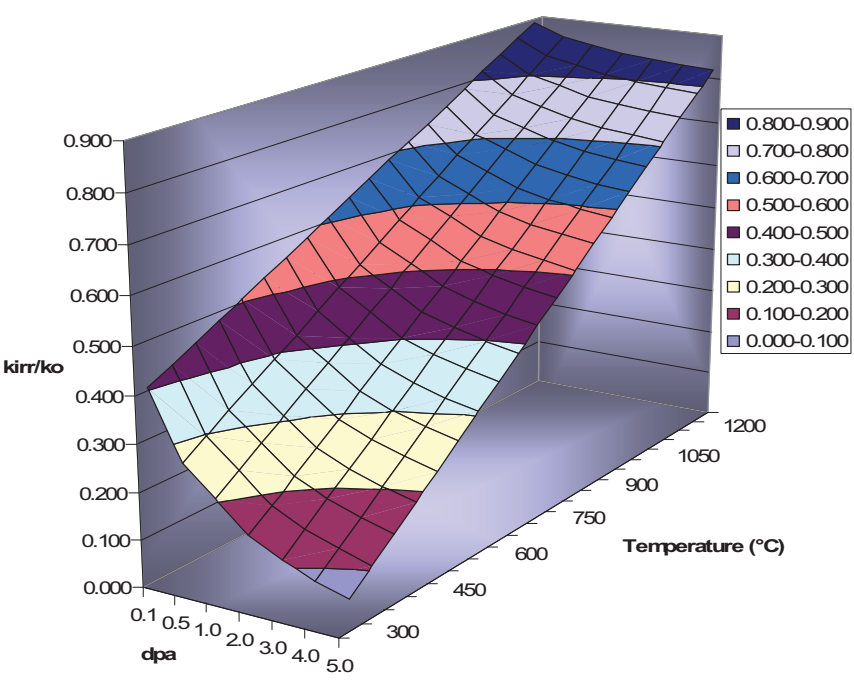

Fig 8. Graphite thermal conductivity plot of ratio of irradiated over unirradiated $\left(k_{i r r} / k_{0}\right)$ varying with temperature and dpa.

The thermal conductivity of the sweep gas was determined using the kinetic theory of gases used by the commercial Computational Fluid Dynamics code FLUENT [8], which gives conductivity $k$ of a gas mixture as a function of the gas constituents $i$ and $j$ according to

$k=\sum_{i} \frac{Y_{i} k_{i}}{\sum_{j} Y_{j} \phi_{i j}}$

where $Y_{i}$ is the mole fraction of gas $i$, and $k_{i}$ is the thermal conductivity of pure gas $i$. The parameter $\phi_{i j}$ in Equation 3 is given by

$\phi_{i j}=\frac{\left[1+\left(\frac{\mu_{i}}{\mu_{j}}\right)^{1 / 2}\left(\frac{M W_{j}}{M W_{i}}\right)^{1 / 4}\right]^{2}}{\left[8\left(1+\frac{M W_{j}}{M W_{i}}\right)\right]^{1 / 2}}$

where $\mu_{i}$ is the viscosity of pure gas $i$ and $M_{w, i}$ is the molecular weight of pure gas $i$. Pure gas properties were taken from Toulukian [9]. Fig 9 shows a plot of the resulting helium/neon sweep gas thermal conductivity versus temperature and mole fraction of helium. The thermal conductivity increases as the helium mole fraction increases and as the temperature increases. 


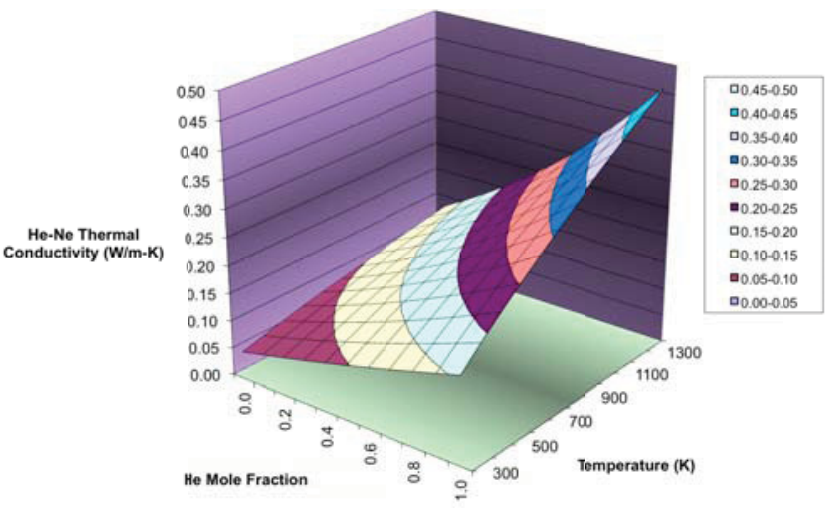

Fig 9. Sweep gas thermal conductivity versus temperature and mole fraction helium.

\section{II.E. Conduction and Radiation Heat Transfer}

The governing equation of steady-state heat transfer for the model is taken as

$$
\begin{aligned}
& \rho c_{p}\left(u_{x} \frac{\partial T}{\partial x}+u_{y} \frac{\partial T}{\partial y}+u_{z} \frac{\partial T}{\partial z}\right)= \\
& \frac{\partial}{\partial x}\left(k(T) \frac{\partial T}{\partial x}\right)+\frac{\partial}{\partial y}\left(k(T) \frac{\partial T}{\partial y}\right)+\frac{\partial}{\partial z}\left(k(T) \frac{\partial T}{\partial z}\right)+Q
\end{aligned}
$$

where $\rho$ is the density, $c_{p}$ is the specific heat, $u_{x}, u_{y}$, and $u_{z}$ are the three directional velocities, $T$ is temperature, $x, y$, and $z$ are directions, $k(T)$ is the thermal conductivity varying with temperature, and $Q$ is the heat source. The velocity of the water $\left(u_{z}\right)$ was taken from Reference [1]. The gas gaps between the graphite holder and the stainlesssteel-retainer sleeve used the above mentioned gas mixture conductivity correlation and were modeled with solid eight-noded brick elements with diffusion heat transfer.

Conduction heat transfer across gas gaps using the ABAQUS * Gap Conductance model was implemented on the gaps between the following surface pairs followed by gap distance:

- fuel compacts and graphite holder $(0.000064 \mathrm{~m})$

- bottom and top graphite spacers with stainless steel retainer sleeve $(0.000965 \mathrm{~m})$

- bottom and top graphite rings with stainless steel retainer sleeve $(0.000965 \mathrm{~m})$

- graphite spacers with graphite spacers on top and bottom $(0.003175 \mathrm{~m})$.

The governing equation for radiation heat transfer across the gas gaps is taken as

$$
q_{\text {net }}=\frac{\sigma\left(T_{1}^{4}-T_{2}^{4}\right)}{\frac{\left(1-\varepsilon_{1}\right)}{\varepsilon_{1} A_{1}}+\frac{1}{A_{1} F_{12}}+\frac{\left(1-\varepsilon_{2}\right)}{\varepsilon_{2} A_{2}}}
$$

where $q$ is the net heat flux, $\sigma$ is the Stephan Boltzmann constant, $T_{1}$ and $T_{2}$ are the surface temperatures, $\varepsilon_{1}$ and $\varepsilon_{2}$ are the emissivities of Surfaces 1 and 2, $A_{1}$ and $A_{2}$ are the areas of Surfaces 1 and 2, and $F_{12}$ is the view factor from Surface 1 to 2 .

Radiation heat transfer using the ABAQUS *Gap Radiation model was implemented on the following surface pairs:

- graphite holder with stainless steel retainer sleeve

- graphite holder with thru tubes

- thru tubes with stainless steel retainer sleeve

- bottom and top graphite spacers with stainless steel retainer sleeve

- bottom and top graphite rings with stainless steel retainer sleeve

- graphite spacers with graphite spacers on top and bottom.

A surface radiation boundary condition using the ABAQUS * Surface Radiation model was placed on the top of the top graphite spacer and the bottom of the bottom graphite spacer and radiated to an infinite medium of $\left(204.4^{\circ} \mathrm{C}\right)$. In order to calibrate the finite element thermal model, the emissivities of the outer surface of the graphite holder and the inner surface of the stainless-steel sleeve were adjusted such that predicted and measured thermocouple (TC) temperatures agreed as closely as possible early in the irradiation before TC drift had become important. View factors for each surface pair were set at 1.0. Emissivity values of 1.0 , and 0.99 for all surfaces gave best agreement between calculation and measurements. In fact, during assembly of the test, the presence of graphite dust was noted on these surfaces, which would serve to raise the emissivities of these surfaces to values closer to their maximum possible value of 1.0. Inspection of the test train during post-irradiation examination showed black surfaces on the stainless steel.

\section{II.F. Base Case Gas Mixture}

The base case has a gas mixture with $80 \%$ neon.

$$
\text { II.G. Fluence }
$$

Graphite and fuel compact material properties vary with fluence. This was taken as Field Variable 2 in the ABAQUS input model, while the neon fraction was taken as Field Variable 1. Base case fluence values are $0.36 \mathrm{x}$ $10^{25} \mathrm{n} / \mathrm{m}^{2}$.

\section{II.H. Component Heat Rates}

The gamma heating for the various components (not including the fuel compacts) were taken from Reference [3]. These heat rates were based on the east lobe power for 
March 13, 2007, for the base case. The water heat rate and the beryllium heat rate were included. These rates raise the water temperature as it flows by the capsule, but are only a small fraction of the total heat. The components on the inside of the water had the greatest effect on the temperature of the fuel compacts and thermocouple locations. The following list shows the component heat rates for the base case. Units are $\left(\mathrm{W} / \mathrm{m}^{3}\right)$. These heat rate values are multiplied by an amplitude multiplier of 1.0 as shown in Table I

\section{TABLE I}

Component Heat Rates $\left(\mathrm{W} / \mathrm{m}^{3}\right)$

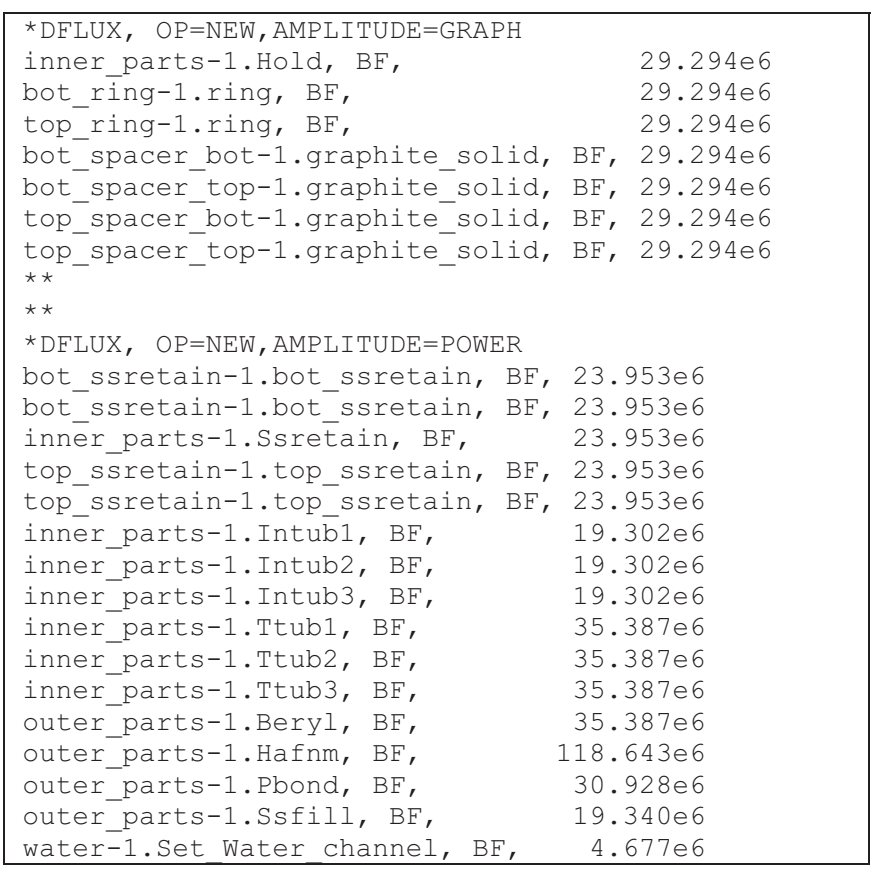

\section{II.I. Fuel Compact Heat Rates}

Fuel compact heat rates were adjusted so that the maximum fuel temperature would be near $1250^{\circ} \mathrm{C}$. All of the compact heat rates had the same value in the capsule of $77.208 \mathrm{e} 6 \mathrm{~W} / \mathrm{m}^{3}$. Table II shows the base case heat rates adjusted for this sensitivity calculation for the fuel compacts and the actual heat rates on March 13, 2007, for the fuel compacts.

\section{TABLE II}

List of fuel compact heat rates for sensitivity calculation and March 13, 2007 heat rates.

\begin{tabular}{|c|c|}
\hline $\begin{array}{c}\text { Base case heat rates adjusted } \\
\text { for sensitivity evaluation } \\
\text { used in ABAQUS }\left(\mathrm{W} / \mathrm{m}^{3}\right)\end{array}$ & $\begin{array}{l}\text { Actual heat rates from } \\
\text { March 13, } 2007 \text { used in } \\
\text { ABAQUS }\left(W / \mathrm{m}^{3}\right)\end{array}$ \\
\hline${ }^{\star} \mathrm{DFLUX}, \mathrm{OP}=\mathrm{NEW}$ & ${ }^{*} \mathrm{DFLUX}, \mathrm{OP}=\mathrm{MOD}$ \\
\hline Stack1-1.S1C4Top,BF， $77.208 \mathrm{e} 6$ & Stack1-1.S1C4Top, BE，78.511e6 \\
\hline Stack1-1.S1C4Bot, BF, $77.208 \mathrm{e} 6$ & Stack1-1.S1C4Bot,BF, $66.944 \mathrm{e} 6$ \\
\hline Stack1-1.S1C3Top, BF, $77.208 \mathrm{e} 6$ & Stack1-1.S1C3Top,BF， $62.763 \mathrm{e} 6$ \\
\hline Stack1-1.S1C3Bot, BF, $77.208 \mathrm{e} 6$ & Stack1-1.S1C3Bot,BE， $61.923 e 6$ \\
\hline Stack1-1.S1C2Top, BF， $77.208 \mathrm{e} 6$ & Stack1-1.S1C2Top,BF， $63.254 \mathrm{e} 6$ \\
\hline Stack1-1.S1C2Bot, BF, $77.208 \mathrm{e} 6$ & Stack1-1.S1C2Bot,BF， $64.060 \mathrm{e} 6$ \\
\hline
\end{tabular}

\begin{tabular}{|c|c|}
\hline Stack1-1.S1C1Top,BF， 77. & Stack1-1.S1C1Top,BF， 70.586e6 \\
\hline Stack1-1.S1C1Bot,BF, $77.208 \mathrm{e} 6$ & Stack1-1.S1C1Bot,BF， $87.634 \mathrm{e} 6$ \\
\hline Stack3-1.S3C4Top,BF，77.208e6 & Stack3-1.S3C4Top,BF， 78.270e6 \\
\hline Stack3-1.S3C4Bot,BF, $77.208 \mathrm{e} 6$ & Stack3-1.S3C4Bot,BF， $66.495 \mathrm{e} 6$ \\
\hline Stack3-1.S3C3Top,BE，77.208e6 & Stack3-1.S3C3Top,BF， 63.099e6 \\
\hline Stack3-1.S3C3Bot,BF，77.208e6 & Stack3-1.S3C3Bot, BF, $62.385 e 6$ \\
\hline Stack3-1.S3C2Top,BE，77.208e6 & Stack3-1.S3C2Top,BE， 63.437e6 \\
\hline Stack3-1.S3C2Bot,BE, $77.208 \mathrm{e} 6$ & Stack3-1.S3C2Bot, BE, $64.741 \mathrm{e} 6$ \\
\hline Stack3-1.S3C1Top,BF，77.208e6 & Stack3-1.S3C1Top,BF， $68.478 \mathrm{e} 6$ \\
\hline Stack3-1.S3C1Bot,BF, $77.208 \mathrm{e} 6$ & Stack3-1.S3C1Bot, BF, $85.233 \mathrm{e} 6$ \\
\hline Stack2-1.S2C4Top,BF， 77.208e6 & Stack2-1.S2C4Top,BF，51.032e6 \\
\hline Stack2-1.S2C4Bot,BF，77.208e6 & Stack2-1.S2C4Bot,BF, $38.822 \mathrm{e} 6$ \\
\hline Stack2-1.S2C3Top,BF，77.208e6 & Stack2-1.S2C3Top,BF, $35.090 \mathrm{e} 6$ \\
\hline Stack2-1.S2C3Bot,BE，77.208e6 & Stack2-1.S2C3Bot, BF， 34.954e6 \\
\hline Stack2-1.S2C2Top, BF， 77.208e6 & Stack2-1.S2C2Top, BF， $35.703 \mathrm{e} 6$ \\
\hline Stack2-1.S2C2Bot,BF，77.208e6 & Stack2-1.S2C2Bot, BF, $36.044 \mathrm{e} 6$ \\
\hline Stack2-1.S2C1Top,BE，77.208e6 & Stack2-1.S2C1Top,BF，40.042e6 \\
\hline Stack2-1.S2C1Bot,BF, $77.208 \mathrm{e} 6$ & Stack2-1.S2C1Bot,BF， $55.606 \mathrm{e} 6$ \\
\hline
\end{tabular}

The ABAQUS model and the MCNP model used to do the physics calculations use the exact same volumes for the fuel compacts. The heating volumes in ABAQUS were described with element groups matching one-half of each compact split at the mid-point from top to bottom. These one-half fuel compact heat rates were input into the ABAQUS input file.

\section{UNCERTAINTIES}

The top five parameters that can be quantified with an uncertainty are shown in Table III with the estimated value. All of these values are the best estimate of what the uncertainty is based on machining tolerance; physics code calculations, mass flow controllers, and engineering experience.

TABLE III

Uncertainties of most significant parameters

\begin{tabular}{|c|c|}
\hline Parameter & Uncertainty (\%) \\
\hline Control gas gap width & 10 \\
Heat rate in fuel compacts & 5 \\
Ne fraction & 2 \\
Graphite Conductivity & 20 \\
Fuel Conductivity & 20 \\
\hline
\end{tabular}

\section{RESULTS}

Results of this sensitivity analysis are shown in Figs 10 through 16. Fig 10 shows a cross-cut view of the temperature contours for the base case. The maximum fuel temperature is $1249.5^{\circ} \mathrm{C}$. The maximum fuel temperature occurs in the fuel compacts near the center of the graphite holder. Fig 11 shows a temperature contour plot of the three fuel stacks for the base case. A constant (even) heat rate of $77.208 \mathrm{e} 6 \mathrm{~W} / \mathrm{m}^{3}$ was input into all of the compacts. It appears that there is not any axial temperature gradient near the center of the fuel compacts. This allows for a good sensitivity study, since there are no abrupt changes in heat rates or axial temperature gradients. 


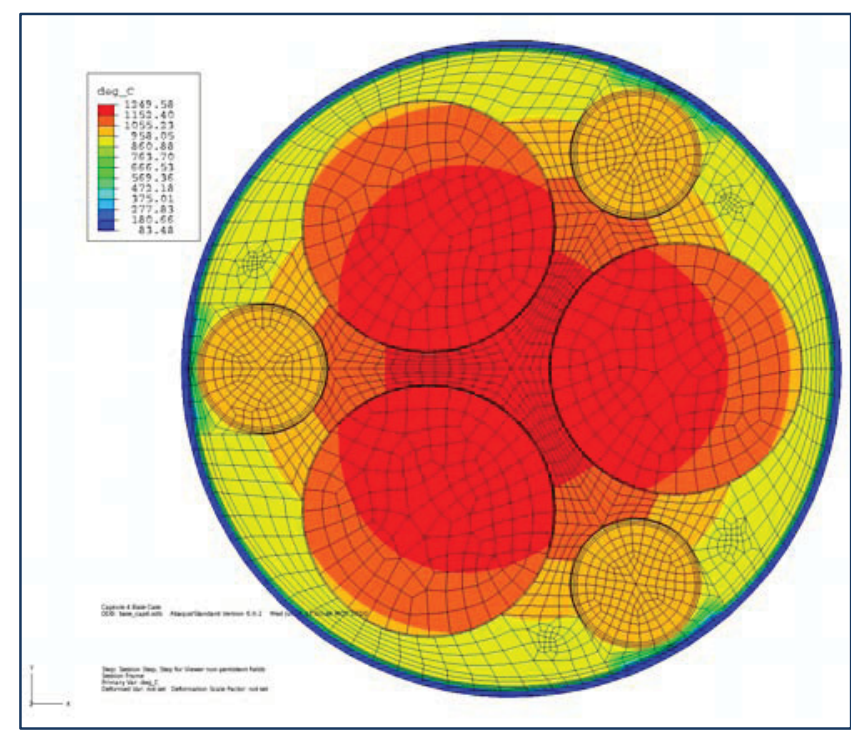

Fig 10. Temperature contour plot $\left({ }^{\circ} \mathrm{C}\right)$ near mid-plane of capsule.

Fig 12 gives a description of the 30 cases that were run. The base case is taken as Case 0 , while Cases 1 and 2 show the temperature change for changing the outer control gas gap by $\pm 10 \%$. This control gas gap was changed by multiplying the thermal conductivity of the control gas by 0.9 and 1.1 to have the effect of moving the gap distance by $\pm 10 \%$ respectively. This was done as a quick method of not having to redo the finite element mesh with a geometrical change. Cases 3 and 4 show the temperature sensitivity by varying the neon fraction by $\pm 10 \%$. Other cases studied include fuel conductivity; graphite conductivity; emissivity of stainless steel, thru tubes, and graphite; and heat rate in fuel, graphite, and components. Cases 20 through 25 show the effect of fluence varying from 0 to $5.0 \times 10^{25} \mathrm{n} / \mathrm{m}^{2}$. Cases 26 and 27 show the sensitivity when the control gas gap is changed by $\pm 20 \%$. A new base case with $80 \%$ helium was performed in Case 28 , with Cases 29 and 30 showing a $\pm 10 \%$ in the helium fraction from Case 28. These last three cases were performed to show the sensitivity to a high fraction of helium at high temperature. Again, the heat rates in the compacts were adjusted to $120.316 \mathrm{e} 6 \mathrm{~W} / \mathrm{m}^{3}$ for the fuel compacts, while the component heat rates were the same as Case 0. This heat rate was found so the peak capsule temperature would again be nearly $1250^{\circ} \mathrm{C}$. Fig 12 shows the resulting capsule average temperature, peak capsule temperature, and $\mathrm{TC} 1, \mathrm{TC} 2$, and $\mathrm{TC} 3$ temperatures. The last five columns show the temperature difference in each of the cases compared to the base case

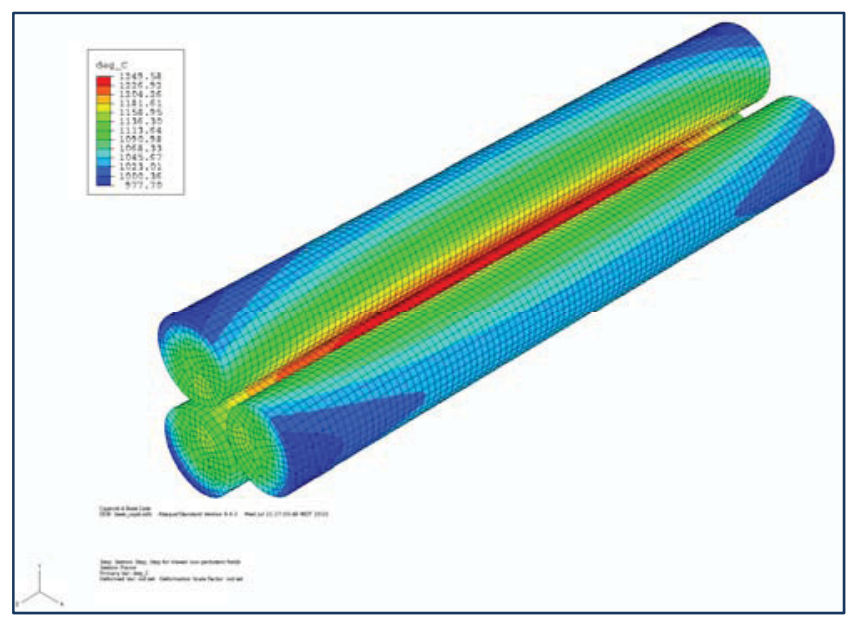

Fig 11. Temperature contour plot $\left({ }^{\circ} \mathrm{C}\right)$ of fuel compacts for base case.

for the average, peak, TC1, TC2, and TC3. The base case is highlighted in gold, while the peak fuel temperatures are highlighted in yellow. The light green highlights show the difference between $\pm 10 \%$ neon compared to $\pm 10 \%$ helium.

Fig 13 shows a tornado plot of the most sensitive temperature variations sorted from largest to smallest. The biggest affect is the control gap distance, heat rate in the fuel, and control gas fraction. The next four are heat rate in the graphite, graphite thermal conductivity, fuel conductivity, and gap conductivity between compacts and graphite holder. The emissivities of the graphite and stainless steel, along with the heat rates in the components and emissivity of the thru tubes are the least sensitive. The total temperature sensitivity for $\pm 20 \%$ outer control gap distance is $130.49^{\circ} \mathrm{C}$, as displayed on the left side of the plot.

Figs 14 and 15 show tornado plots for the temperature sensitivity for TC2 and capsule average temperature, respectively. The order of the sensitivity remains the same for all three plots except the $5^{\text {th }}$ and $6^{\text {th }}$ places are reversed on the capsule average temperature plot in Figure 15.

Fig 16 shows the peak fuel temperature sensitivity based on fluence. The fluence values have an effect on the thermal conductivity of the fuel compacts and the graphite components. The thermal conductivity of the fuel compacts and the graphite varying with fluence and temperature are shown in Figs 6 and 8 (above). It appears that the overall trend is for the conductivity to decrease and cause higher temperatures. 


\begin{tabular}{|c|c|c|c|c|c|c|c|c|c|c|c|}
\hline Case \# & Description & CAP_AVE & AP_MAX & TC1 & TC2 & TC3 & $\Delta$ cap_ave & $\Delta$ cap_max & $\Delta \mathrm{TC1}$ & $\Delta \mathrm{TC} 2$ & $\Delta \mathrm{TC3}$ \\
\hline 0 & Base Case & $11 \overline{1.26}$ & $\overline{1248.72}$ & 922.92 & 1226.21 & 922.42 & 0.00 & 0.00 & 0.00 & 0.00 & 0.00 \\
\hline 1 & 1.1 X outer control gap distance & 1182.96 & 1282.33 & 957.88 & 1259.82 & 957.43 & 31.70 & 33.61 & 34.96 & 33.61 & 35.01 \\
\hline 2 & 0.9 X outer control gap distance & 1121.61 & 1217.24 & 890.17 & 1194.73 & 889.62 & -29.65 & -31.48 & -32.75 & -31.48 & -32.80 \\
\hline 3 & 1.1 X Ne fraction & 1198.02 & 1295.51 & 961.57 & 1268.94 & 961.11 & 46.76 & 46.79 & 38.65 & 42.73 & 38.69 \\
\hline 4 & $0.9 \times \mathrm{Ne}$ fraction & 1103.48 & 1200.80 & 882.59 & 1181.85 & 882.03 & -47.78 & -47.92 & -40.33 & -44.36 & -40.39 \\
\hline 5 & 1.1 X FUEL conductivity & 1145.43 & 1237.47 & 922.15 & 1217.51 & 921.65 & -5.83 & -11.25 & -0.77 & -8.70 & -0.77 \\
\hline 6 & 0.9 X FUEL conductivity & 1158.21 & 1261.90 & 923.78 & 1236.21 & 923.28 & 6.95 & 13.18 & 0.86 & 10.00 & 0.86 \\
\hline 7 & 1.1 X GRAPHITE (7.0\% Boron) conductivity & 1142.77 & 1236.64 & 919.94 & 1210.68 & 919.45 & -8.49 & -12.08 & -2.98 & -15.53 & -2.97 \\
\hline 8 & 0.9 X GRAPHITE (7.0\% Boron) conductivity & 1161.06 & 1262.43 & 926.40 & 1243.61 & 925.89 & 9.80 & 13.71 & 3.48 & 17.40 & 3.47 \\
\hline 9 & 1.1 X gap conductivity INT4 (holder/compact gap) & 1142.30 & 1240.88 & 922.66 & 1221.31 & 922.16 & -8.96 & -7.84 & -0.26 & -4.90 & -0.26 \\
\hline 10 & 0.9 X gap conductivity INT4 (holder/compact gap) & 1162.11 & 1258.29 & 923.22 & 1231.98 & 922.72 & 10.85 & 9.57 & 0.30 & 5.77 & 0.30 \\
\hline 11 & 0.9 Xemissivity of SS retain & 1160.82 & 1258.50 & 933.24 & 1235.99 & 932.73 & 9.56 & 9.78 & 10.32 & 9.78 & 10.31 \\
\hline 12 & 0.9 Xemissivity of Thru Tubes & 1152.88 & 1250.65 & 924.49 & 1228.23 & 923.99 & 1.62 & 1.93 & 1.57 & 2.02 & 1.57 \\
\hline 13 & 0.9 Xemissivity of graphite & 1160.67 & 1257.54 & 932.49 & 1234.99 & 931.99 & 9.41 & 8.82 & 9.57 & 8.78 & 9.57 \\
\hline 14 & $1.1 \mathrm{X}$ heat rate in fuel & 1204.98 & 1310.60 & 959.13 & 1284.20 & 958.64 & 53.72 & 61.88 & 36.21 & 57.99 & 36.22 \\
\hline 15 & $0.9 \times$ heat rate in fuel & 1095.43 & 1184.40 & 884.82 & 1165.87 & 884.31 & -55.83 & -64.32 & -38.10 & -60.34 & -38.11 \\
\hline 16 & 1.1 $\mathrm{X}$ heat rate in graphite & 1164.17 & 1262.29 & 935.37 & 1241.17 & 934.87 & 12.91 & 13.57 & 12.45 & 14.96 & 12.45 \\
\hline 17 & $0.9 \mathrm{X}$ heat rate in graphite & 1138.15 & 1234.97 & 910.24 & 1211.05 & 909.74 & -13.11 & -13.75 & -12.68 & -15.16 & -12.68 \\
\hline 18 & 1.1 $\mathrm{X}$ heat rate in components & 1154.14 & 1251.99 & 925.94 & 1229.59 & 925.39 & 2.88 & 3.27 & 3.02 & 3.38 & 2.97 \\
\hline 19 & $0.9 \mathrm{X}$ heat rate in components & 1148.37 & 1245.44 & 919.90 & 1222.82 & 919.44 & -2.89 & -3.28 & -3.02 & -3.39 & -2.98 \\
\hline 20 & 0.0 fluence & 1119.73 & 1205.97 & 910.75 & 1176.13 & 910.27 & -31.53 & -42.75 & -12.17 & -50.08 & -12.15 \\
\hline 21 & 0.001 fluence & 1126.43 & 1215.13 & 913.35 & 1187.77 & 912.86 & -24.83 & -33.59 & -9.57 & -38.44 & -9.56 \\
\hline 22 & 0.01 fluence & 1135.05 & 1226.84 & 916.80 & 1202.07 & 916.31 & -16.21 & -21.88 & -6.12 & -24.14 & -6.11 \\
\hline 23 & 0.1 fluence & 1145.71 & 1240.99 & 921.14 & 1218.49 & 920.64 & -5.55 & -7.73 & -1.78 & -7.72 & -1.78 \\
\hline 24 & 1.0 fluence & 1164.93 & 1266.97 & 927.75 & 1244.75 & 927.24 & 13.67 & 18.25 & 4.83 & 18.54 & 4.82 \\
\hline 25 & 5.0 fluence & 1191.86 & 1301.01 & 935.48 & 1277.08 & 934.97 & 40.60 & 52.29 & 12.56 & 50.87 & 12.55 \\
\hline 26 & $1.2 \mathrm{X}$ outer control gap distance & 1216.92 & 1318.33 & 995.28 & 1295.93 & 994.87 & 65.66 & 69.61 & 72.36 & 69.72 & 72.45 \\
\hline 27 & 0.8 X outer control gap distance & 1093.92 & 1187.84 & 859.67 & 1165.28 & 859.09 & -57.34 & -60.88 & -63.25 & -60.93 & -63.33 \\
\hline 28 & New Base $80 \%$ Helium $1250 \mathrm{C}$ & 1107.24 & 1250.09 & 837.12 & 1231.12 & 836.38 & 0.00 & 0.00 & 0.00 & 0.00 & 0.00 \\
\hline 29 & 1.1 $\mathrm{X} \mathrm{He}$ fraction from Case 28 & 1063.24 & 1206.04 & 799.10 & 1189.17 & 798.32 & -44.00 & -44.05 & -38.02 & -41.95 & -38.06 \\
\hline 30 & $0.9 \times \mathrm{He}$ fraction from Case 28 & 1151.93 & 1294.67 & 875.93 & 1273.43 & 875.22 & 44.69 & 44.58 & 38.81 & 42.31 & 38.84 \\
\hline
\end{tabular}

Fig 12. Description of cases with temperature results in $\left({ }^{\circ} \mathrm{C}\right)$.

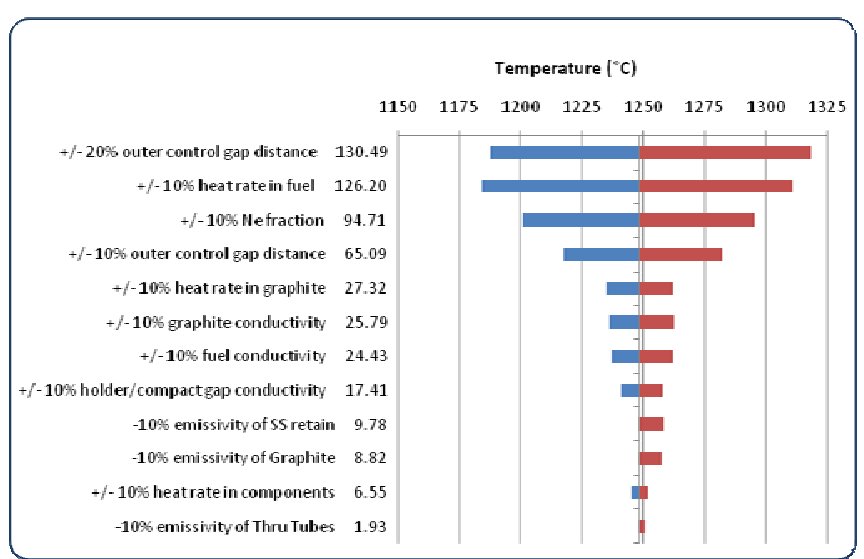

Fig 13. Tornado plot of peak fuel temperature $\left({ }^{\circ} \mathrm{C}\right)$ sensitivity.

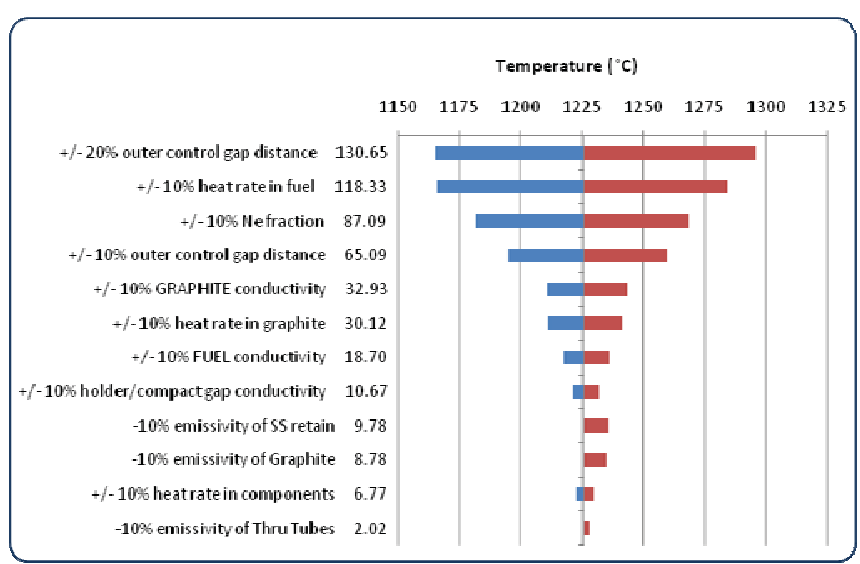

Fig 14. Tornado plot of $\mathrm{TC} 2$ temperature $\left({ }^{\circ} \mathrm{C}\right)$ sensitivity. 


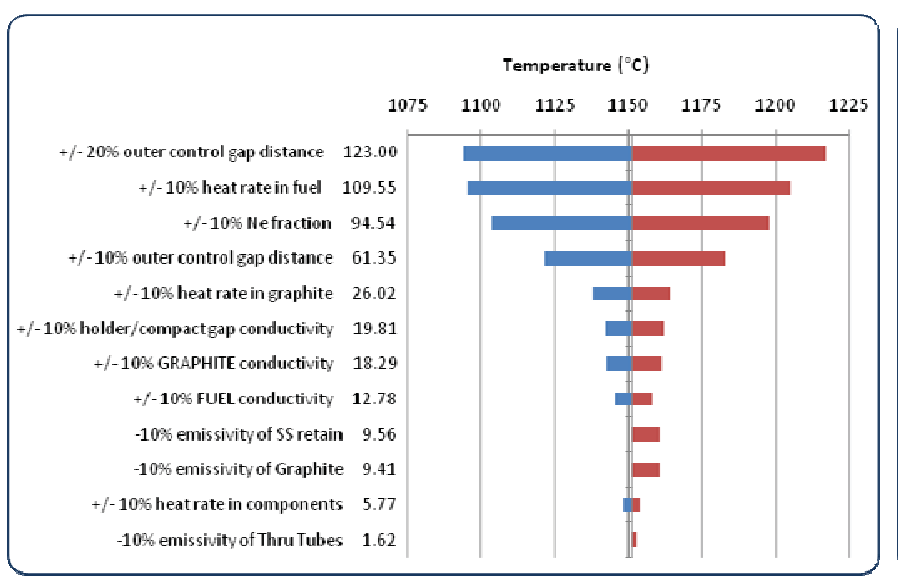

Fig 15. Tornado plot of capsule average temperature $\left({ }^{\circ} \mathrm{C}\right)$ sensitivity.

\section{CONCLUSIONS}

A temperature sensitivity evaluation has been performed for the AGR-1 fuel experiment on an individual capsule. A series of cases were compared to a base case by varying different input parameters into the ABAQUS finite element thermal model. These input parameters were varied by $\pm 10 \%$ to show the temperature sensitivity to each one. The most sensitive parameters are the outer control gap distance, heat rate in the fuel compacts, and Neon gas fraction. Thermal conductivity of the compacts and graphite holder were in the middle of the list for sensitivity. The smallest effects were for the emissivities of the stainless steel, graphite, and thru tubes. Sensitivity calculations were also performed varying with fluence. These calculations showed a general temperature rise with an increase in fluence. This is a result of the thermal conductivity of the fuel compacts and graphite holder varying with fluence.

\section{ACKNOWLEDGMENT}

Work supported by the U.S. Department of Energy, NGNP Program, Idaho Operations Office Contract DE-AC07-05ID14517.

\section{REFERENCES}

1. G.L. Hawkes, et. al., "Daily Thermal Results of the AGR-1 Experiment in the Advanced Test Reactor," paper \# 1039, ANS Annual Conference, San Diego, CA, June 2010.

2. Dassault Systèmes, ABAQUS Version 6.8-2, www.simulia.com or www.abaqus.com, Providence, Rhode Island, 2007.

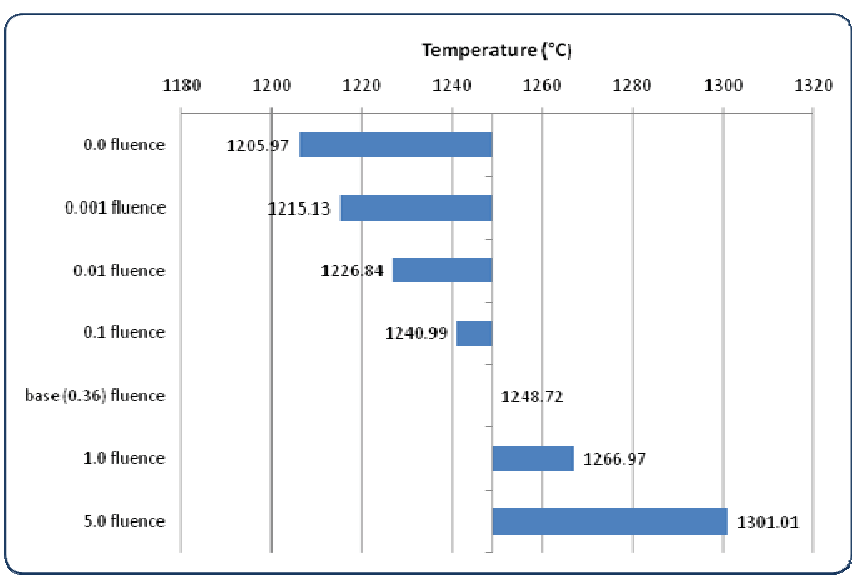

Fig 16. Plot of peak fuel temperature sensitivity based on fluence.

3. J. W. Sterbentz, et. al., "Monte Carlo Depletion Calculation for the AGR-1 TRISO Particle Irradiation Test," paper \# 1308, ANS Annual Conference, San Diego, CA, June 2010

4. R. Gontard and H. Nabielek, "Performance Evaluation of Modern HTR TRISO Fuels," Forschungszentrum Jülich GmbH, HTA-IB-05/90, July 31, 1990.

5. T. L. Thompson, Letter from GrafTech to the Idaho National Laboratory, July 13, 2006.

6. L. L. Snead and T. D. Burchell, "Reduction in Thermal Conductivity Due to Neutron Irradiation, 22nd Biennial Conference on Carbon, Extended Abstracts (1995) 774-775.

7. J. W. Sterbentz, "Fast Flux to DPA Multiplier," Email communication to G.L. Hawkes, August 5, 2009.

8. Fluent Inc., "Fluent 6.3 User's Guide," Lebanon, NH, September 2006.

9. Y. S. Touloukian, "Thermophysical Properties of Matter, Volume 3 - Thermal Conductivity," Thermophysical Properties Research Center, Purdue University, 1977. 